\title{
A INTEGRAÇÃO ENTRE POLÍTICAS PÚBLICAS DE PROTEÇÃO SOCIAL COM EDUCAÇÃO AMBIENTAL
}

Aloisio Ruscheinsky ${ }^{1}$

Manoella Cará Treis ${ }^{2}$

Resumo: $O$ contexto das políticas públicas ambientais e da emergência de desastres socioambientais incidem na qualidade de vida, com destaque às causas e ações para mitigar. O objetivo do estudo é compreender a interface da Educação Ambiental com as políticas públicas, com as práticas sociais, o bem-estar social. Foram utilizados os dados de documentos múltiplos, assim como observação de campo e entrevistas semiestruturadas. Um olhar da Educação Ambiental destaca as consequências das inundações como relacionadas à organização social mais do que aos efeitos da natureza. Os desastres são reflexos das ações e práticas sociais, e desafiam a ação do poder público, as iniciativas de Educação Ambiental e as alternativas desenhadas por atores sociais.

Palavras-chave: Educação Ambiental; Políticas Públicas; Desastres; Práticas Sociais; Transversalidade.

Abstract: The context of public environmental policies and the emergence of socio-environmental disasters affects quality of life, with emphasis on causes and actions to mitigate. The objective of the study is to understand the interface between environmental education and public policies, with social practices, and social well-being. Data from multiple documents were used, as well as field observation and semi-structured interviews. A look at environmental education highlights the consequences of floods as related to social organization rather than to the actions of nature. Disasters are a reflection of social actions and practices, and they challenge the action of public authorities, environmental education initiatives and alternatives designed by social actors.

Keywords: Environmental Education; Public Policy; Disasters; Social Practices, Transversality.

\footnotetext{
1 Universidade do Vale dos Sinos. E-mail: aloisioruscheinsky@gmail.com, Link para o Lattes: http://lattes.cnpq.br/0364210650396629

2UFRGS. E-mail: treismanu@gmail.com

Link para o Lattes: http://lattes.cnpq.br/8545662885272954
} 


\section{Introdução}

A pesquisa foi desenvolvida tendo como propósitos conferir a possibilidade de integração entre políticas públicas de proteção social dos cidadãos concomitantemente com processos de Educação Ambiental e que está relacionada às concepções, imaginários e práticas sociais. Portanto, 0 objeto desta investigação e do texto reporta-se ao nexo passível de ser construído em meio a eventos desfavoráveis entre processos socialmente ancorados de proteção ambiental e social e reflexão empreendida para compreender como ações humanas são relevantes para a legitimação de equipamentos sociotécnicos.

O texto deriva da atividade de investigação e foram mapeadas as multíplices e díspares políticas ambientais, enfocando particularmente os cuidados com a água potável, com vistas aos usos conflitivos do território. Ora, tais cuidados de qualquer modo resultam de um processo educativo e requer uma interpretação do nexo sociedade-natureza. Das atividades urbanas, sejam industriais, comerciais ou cotidianas dos indivíduos, decorrem formas expressas de degradação gradual da qualidade da água das bacias hidrográficas, origem usual do abastecimento. Em consonância com a ampliação da distribuição de mercadorias e a dilatação do consumo advém os respectivos impactos e riscos socioambientais gerando a proliferação individual e coletiva de dejetos sólidos, líquidos e gazes.

Os diques construídos na cidade de São Leopoldo como proteção ante as inundações periódicas acentuaram um contraponto entre sociedade e ambiente: a barreira entre a cidade e o rio permitiu se criar o imaginário de que os cidadãos se encontram de costas para a potabilidade das águas. 0 fenômeno socioambiental gerado por uma obra urbanística, a inquietação em face de alagamentos e os dilemas adjacentes podem efetivamente fazer eclodir temas geradores de redimensionamento da concepção ambiental ou noções mediadoras para a desnudar interfaces e paradoxos. Um processo social com endosso do saber ambiental peculiar pode emergir alicerçado na ótica que reconhece como imprescindível a apropriação e uso dos bens naturais para o sustento do cotidiano. Os impactos e depredação estão ao encalço da sustentabilidade almejada, razão de ser das proposições de Educação Ambiental como uma perspectiva transversal.

O autor atina compreender uma situação histórica de práticas sociais no Vale do Rio dos Sinos, no sul do Brasil, num contexto em que incidem a demanda por qualidade de vida amparada ambientalmente e as respectivas políticas públicas que visam mitigar os impactos de desastres socioambientais. $\mathrm{Na}$ associação entre tais fatores brotam os respectivos dramas e tramas humanos, bem como conexões com o campo político em que se movem atores sociais. As demandas concernentes aos cidadãos em situação de multíplices vulnerabilidades fundam a discussão e apresentação de alguns aspectos da gestão do poder público em períodos de inundação, no caso considerando em especial a região norte de São Leopoldo/RS. $\mathrm{Na}$ exposição há um esforço para 
recorrer a dados a serem utilizados a partir de alguns diagnósticos, a percepção do processo pelas pessoas atingidas, bem como a sua relação com a questão da proteção de bens ambientais.

$O$ enfoque da abordagem encontra seus fundamentos analíticos nos aportes dados pelas lentes das ciências sociais. Em especial da sociologia ambiental que por sua vez é um alicerce para implementar projetos de Educação Ambiental. As ciências sociais e humanas enredadas no iluminismo, bem como a visão junto aos processos educativos, foram vistas como tendo um olhar de estranhamento em face do tema ambiental. Tendo em vista a prevalência da dimensão antropocêntrica, acatada de forma acrítica, a ecologia era vista como campo por excelência de outras áreas do conhecimento. Todavia, a emergência de dinâmicas de Educação Ambiental fez compreender imbricações entre questões plurais de ordem ética, política, cultural, pedagógica e simbólica.

A metodologia empregada na realização dos procedimentos da pesquisa para escorar argumentos neste trabalho consiste na escolha de ferramentas que amparem a observação do campo empírico, bem como as categorias de interpretação para afiançar a abordagem científica. Dados secundários compilados por pesquisa bibliográfica e documental formaram o corpus da primeira etapa para uma aproximação consistente aos fenômenos socioambientais e reconhecimento de um espaço social de realização da Educação Ambiental. Os dados auferidos da realidade complexa e contingente foram recolhidos por meio das observações e anotações em campo. Igualmente, foram realizadas entrevistas com um grupo qualificado de agentes da Educação Ambiental, bem como especialistas com responsabilidade na educação e gestão ambiental. $O$ artigo baseia-se também na experiência de praticantes na implementação de projetos de Educação Ambiental, cuja ótica permeia a tecitura da narrativa. Por fim, parece evidente que não está em questão apresentar os resultados a propósito de caso de sucesso, mas antes os percalços da trajetória e confrontação diante de intervenções públicas e seus efeitos polissêmicos. Neste sentido se aplica uma afirmação de Floriani (2019, p.31).

uma abordagem especial em que se possa desenvolver uma interpretação, mesmo que panorâmica - pela complexidade que tal exercício implica - sobre o que designamos por relação sujeito-objeto e as consequentes formas ou resultados que essa relação provoca na sua aplicação, quando desenvolvidas pelos sistemas de produção do conhecimento ....

E mais do que isto, a situação trágica do ponto de vista da vulnerabilidade ambiental, nos encontramos mais próximos de batalhas, talvez não declaradas, do que da fluidez entre sociedade-natureza, razão pela qual tão pouco parece resultar da diplomacia de negociação da pilhagem. O intuito de modificar comportamentos e hábitos da população compõe-se de 
mecanismos de diálogo e de digladiar com práticas sociais adversas. A conflagração de ações para uma consistente oposição à degradação do ambiente e uma construção de iniciativas de Educação Ambiental pode revelarse um campo efervescente e promissor. Para consolidar este horizonte, a realização e sistematização de pesquisas parece decorrer da importância de fundamentar experimentos em diferentes níveis. Estudar e sistematizar conhecimentos pode favorecer o comprometimento dos atingidos com as precauções e as soluções em face de um desastre socioambiental.

O debate em torno de políticas públicas como uma estratégica ação para a prevenção e para inibir consequências desastrosas de flagelo decorrentes de inundações detém o seu sentido atrelado a áreas urbanas indevidamente consolidadas, bem como o seu horizonte pode coincidir com Educação Ambiental ou mesmo divagar em direções conflitantes. Neste sentido, o texto discute algumas possibilidades de interfaces entre políticas públicas, recursos hídricos, bem-estar social e educação junto à bacia do Rio dos Sinos. Ora, os atores sociais e ambientais se defrontam com um paradoxo: medidas de mitigação adotadas para a proteção contra as inundações implica em mecanismos de (des)proteção da água potável uma vez que se sucede a ocupação das áreas anteriormente alagadiças?

\section{Mediações sociais e políticas públicas sobre a temática ambiental}

Cabe inicialmente destacar a crítica à interpretação da realidade pelo viés da dicotomia Sociedade-Natureza, nem a primeira (Sociedade/Sujeito) pode prescindir da segunda (Natureza/Objeto), nem esta ser tomada como um âmbito intocado, unificado e homogêneo, mas também um sujeito múltiplo. A dicotomia pode ser rechaçada nas elaborações retóricas, porém muito presente nas práticas sociais, ao mesmo tempo que desafia a formulação e implementação de políticas públicas ambientais ${ }^{3}$. Outra contradição a explicitar em demandas e desejos individuais e obras institucionais e administrativas: cursos d'água são canalizados, retificados, encobertos; 0 solo impermeabilizado para não sujar os pés; os resíduos e esgoto tratados, mas "longe do meu quintal"; a maior parte dos impactos são acompanhados de mecanismos de disfarce.

Diante deste fenômeno que também afeta diretamente as práticas de Educação Ambiental "a única solução é reescrever, repensar, relocalizar e reterritorializar a noção de terra. O que constitui um território ao qual as pessoas estão apegadas e as quais estão prontas para defender? E não uma natureza externa, mas o território sob seus pés" (LATOUR et al., 2018, 357). Portanto, essa visão anacrônica, sobrevive na contemporaneidade, como um

3 Em vários cursos d'água houve intervenções com obras de micro drenagem, alargamento ou retificação de canal, galerias subterrâneas para esgotamento pluvial, recuperação urbanística de margens deterioradas, incremento da rede coletora de esgoto, reassentamento de famílias afetadas pelas inundações, entre outras.

Revbea, São Paulo, V. 16, № 4: 205-226, 2021. 
dos pilares do conhecimento e de domínio sobre a realidade factual, motiva a paralisia frente aos fenômenos como: a perda de biodiversidade, a degradação do solo, a ocupação pela urbanização de espaços impróprios como os banhados, experimentos superficiais de Educação Ambiental, a poluição e suposta escassez de água potável e outros temas ambientais.

$\mathrm{Na}$ realidade, onde quer que seja, ao lidar com um fenômeno tido como natural ou ambiental, encontra-se de imediato elos, vínculos, relações com as práticas humanas. Da mesma forma, ao projetar políticas públicas onde, de alguma forma, se abordam os entrelaçamentos sociais para a dignidade humana pode-se desvendar mecanismos e instâncias de associação, integração, mediação com o ecossistema. Esta indissociabilidade é apontada por Latour (2014) como uma aliança referendada socialmente, relativizando a segmentação entre o subjetivo e o objetivo, imputando à ação humana os riscos ambientais, enfim, sendo propício para a emergência de possibilidades compreensivas e inteligibilidades. A polarização mostra que estas temáticas estão no centro dos conflitos de interpretação.

A partir desta abordagem fica evidenciado que as práticas sociais confluem em redes entrelaçadas, ou elementos de sua composição. Portanto, a sua compreensão requer entrever um processo de construção que inclui os bens naturais. Todavia, isto não é algo evidente no cotidiano, pois as relações contingentes não são reveladas ao olhar que observa os fenômenos sociais e ambientais pela aparência. $\mathrm{O}$ ato de respeitar os espaços do rio, de trocar de lâmpada, de adotar medidas mitigadoras, de colaborar com a coleta seletiva, de cuidar da água entre outras mais radicais conecta-se com o destino do planeta por meio da reflexividade. Usualmente, as questões ambientais são lidas somente como produtos acabados, ou seja, como fatos dados, acontecido ou consumado. Uma visão de complexidade vincula os fenômenos socioambientais com a sua composição/trajetória ou múltiplos nexos socialmente ancorados. Isto é, a reflexividade permite captar as associações entre os atores, os acordos com que/quem para engendrar demandas ambientais, os instrumentos que imputam relacionamentos entre sociedade, mercado e Estado. Este também é o enredo da Educação Ambiental, sem olvidar da expressão utilizada por Nédélec, Simonneaux e Molinatti (2017): "incerteza reflexiva da incerteza".

O projeto engenhoso de contenção de alagamentos de espaços urbanizados, destaca-se num formato ou desenho de efetivação de políticas públicas e consistiu na construção histórica de um sistema de contenção ou diques $^{4}$. A engrenagem é composta de taludes, de comportas e com bombas

\footnotetext{
${ }^{4} \mathrm{Na}$ cidade de São Leopoldo foi construído uma contenção nos anos 60, para proteger o centro da cidade e nos anos 80 o lado norte para diminuir os alagamentos. A empresa Wittler Engenharia e Hidrologia informa que o Projeto Contra Cheias protegeu a ocupação urbana de 1.650 hectares ao custo de $\mathrm{Cr} \$ 470$ milhões, em 1978, atualizado em 2004 para $\mathrm{R} \$ 180$ milhões. Para o sustento dos equipamentos, conforme o Art. 3 do Decreto 3640/02, o total de custos anuais foi de $R \$ 924.600,00$. Dados disponíveis em http://www. wittler.com.br/engenharia/site/default.asp?TroncolD=906480\&SecaolD=707260. Acesso fev. de 2020.
} 
para drenagens de águas pluviais. Ora, por mais que parece uma obra pronta e acabada temos a pretensão de apontar que a Educação Ambiental possui neste evento uma atribuição permanente. Ao longo dos anos os diques alteram o tipo de percepção quanto ao relacionamento histórico com o rio, pois além de proteger das ameaças periódicas, transforma os significados e progressivamente a cidade fique de costas para o rio e os seus habitantes alienados à sua sorte. Este empreendimento com financiamento internacional incrementou as circunstâncias em que a vida do rio passou a um dos obstáculos à qualidade de vida, em lugar de percebê-lo como parte do espaço urbanizado e integrante de sua paisagem e território.

Os riscos sempre representam potenciais danos ou prejuízos, bem como a probabilidade de que de forma imprevisível se concretizem, contando com certa vulnerabilidade do sistema em face dos efeitos adversos. Uma política ambiental consiste em uma atividade planejada ou uma orientação arquitetada para o enfrentamento político de uma questão socioambiental, supondo um tratamento estratégico porquanto uma resolução de relevância. De acordo com Secchi (2016) possui a intencionalidade expressa como resposta a um eminente impasse com aspectos fundamentais para o bem-estar. As questões que os espaços urbanos aportam para a sustentabilidade ambiental possuem uma íntima conexão com as demandas sociais, talvez configuradas mais do que demandas socioambientais.

Nesta ótica os fenômenos observados na pesquisa empírica conduzem a gestão estatal para a efetivação de ações estratégicas, mediadas por qualificadas políticas públicas ambientais, assentadas na vigência de direitos humanos. Em relação aos desastres provocados pelas inundações, que ocorrem periodicamente na região em destaque, se apresentam como os principais eventos adversos na área ambiental. Diante do processo de urbanização em curso existem ações paliativas no mais das vezes e que dizem respeito às áreas de risco de inundações. Por mais que educadores e gestores insistam no mantra da prevenção e adequado funcionamento dos implementos técnicos, podem ocorrer falhas de diversas ordens. Desta forma, ocorrem alagamentos em casos no mais das vezes pontuais, como o caso típico onde uma das bombas deixou de funcionar em decorrência da pane na rede de energia elétrica.

Um dos maiores problemas enfrentados são os descartes nos arroios, nas encostas, nos banhados e na rua, isso impede que a água flua naturalmente, dilatando os efeitos dos alagamentos. Desta maneira, existem estruturas físicas, relacionais e culturais a serem monitoradas de maneira diuturna, permanente e adequadamente para mitigar os efeitos na sociedade assimétrica que se vê forjada a uma resposta direta aos dejetos ou resíduos.

O programa coleta seletiva consolida uma das ações do poder público como mecanismo articulado para minimizar decorrências atreladas à circulação 
de mercadorias ${ }^{5}$. A interrogação do ponto de vista da Educação Ambiental se refere às implicações para o nexo sociedade e natureza, ou em que medida este processo de coleta coletiva compreende um processo de mudança na relação com os bens ambientais. Para situar o leitor, desde 2009 em São Leopoldo este programa agrega poder público, associações da sociedade civil e empresas. Este se alastra por toda malha urbana acontecendo porta a porta, com frequência mínima semanal e em áreas de maior volume sucede duas ou três vezes. Inicialmente se efetuava com atividade de catadores organizados, porém por questões de logística e o efeito sobre o desgaste de saúde, passou ao uso de caminhões adaptados. Os resultados no percurso por 16 setores são encaminhados às cinco Associações e Cooperativas conveniadas distribuídas estrategicamente no território urbano. Ora, tudo isto supõe a existência de um processo de Educação Ambiental, mesmo que seja difuso.

Ao tratar do gerenciamento de risco pode-se mover a noção de governança de riscos, a qual se reporta à prevenção, à precaução e à educação nos referidos cenários urbanos. Esta noção implica dar atenção especial uma vez que diz respeito a um contexto que apresenta incertezas, ameaças, precarização (NÉDÉLEC; SIMONNEAUX; MOLINATTI, 2017). A precaução se aloca como ação comedida, possibilita algum grau de previsão e possui uma inevitável carência, sendo de acordo com os autores, oportunidade de tentar diagnosticar incertezas em face da complexidade e da pluralidade de respostas possíveis.

A gestão de desastres socioambientais circunscreve uma incerteza acentuada e como tal uma tênue possibilidade de nexo com Educação Ambiental. $\mathrm{Na}$ governança de riscos as controvérsias sociotécnicas se multiplicam devido ao panorama de incertezas (NÉDÉLEC; SIMONNEAUX; MOLINATTI, 2017), bem como as circunstâncias estão minando os mecanismos ou instrumentos em face das questões que exigem escolha e deliberação. Quanto mais as controvérsias atingem também aos cientistas, aos decisores burocráticos maior a tendência de silenciar ou neutralizar outros atores sociais, como aqueles devotados pela Educação Ambiental. O risco imposto, não somente aos aspectos ambientais, mas também às decisões técnicas que se localizam num campo de incertezas para dissolver controvérsias e enigmas cruciais fragilizam a legitimidade do conhecimento científico e dos atores políticos em suas deliberações e por esta razão tendem a olvidar o debate democrático.

Em face de políticas públicas Poul Harremoës et al. (2002) apresentam doze lições referentes à precaução para encetar um processo de avaliação. Nesta abordagem tentam contrabalançar tanto à ignorância como à incerteza e assim tentar auscultar a linguagem e os avisos da natureza e as utopias humanas. Assim como contemplar as lacunas do conhecimento, reduzir

5 Campos e Alves (2019) descrevem as formas de participação, o entrelaçamento com a Educação Ambiental na organização da coleta seletiva de resíduos sólidos; 
obstáculos na aprendizagem, assegurar que o real esteja no centro das ponderações, arrolar os aspectos favoráveis e contrários reivindicados, observar e avaliar as alternativas e propor soluções. O aprendizado da Educação Ambiental vai além dos especialistas - o saber local tende a ser validado, considerando o lugar social das práticas socioambientais (FLORIANI, 2019), para além de apresentar visões políticas e econômicas, reduzir obstáculos à aprendizagem e suas ações consequentes. Particularmente os pesquisadores ambientais como intermediários do conhecimento fornecem informações objetivas aos formuladores de políticas setoriais e aos gestores governamentais.

O alerta à população devido ao risco de enchentes tem como contraponto as toneladas de descartes pós-consumo nos equipamentos para o bombeamento, o maior ápice para os alagamentos na região; razão pela qual questiona-se os processos de educação uma vez que é do conhecimento que os resíduos descartados de forma inadequada geram parte dos problemas dos alagamentos. Os órgãos públicos possuem equipes de prontidão para a retirada desses descartes acumulados e ao mesmo tempo tem sido levado ao público peças de publicidade ambiental, que se dirigem diretamente às escolas e outros espaços.

A gestão das inundações ${ }^{6}$ depende da ação de órgãos, como o SEMAE (Serviço Municipal de Água e Esgotos de São Leopoldo/RS), a Prefeitura, a Defesa Civil, o Ministério Público e o Comitesinos (Comitê de Gerenciamento da Bacia Hidrográfica do Rio dos Sinos). Estes buscam a racionalidade do sistema de proteção. Na prática se afiança que a Educação Ambiental viria em socorro a aspectos práticos como os cuidados com a manutenção dos taludes/diques e das estruturas de drenagem, além de pugnar para diminuir a impermeabilização e a ocupação das planícies de inundação ${ }^{7}$. Isto além das tarefas para a disposição correta de resíduos como prática ambiental com tantos outros benefícios.

A introdução da política de Educação Ambiental usualmente bemintencionada e projetada para demandas de setores da população, contudo no mais das vezes subdimensiona as múltiplas insuficiências dos sujeitos cidadãos. Estas circunstâncias foram denominadas por Latour e outros (2018) jogadores enfraquecidos constituídos por humanos e não humanos ou sujeito insuficiente em face do esgotamento político (PINTO, 1999). Na observação de

6 O ano de 2013 é um marco das inundações após a conclusão do dique lado norte nos anos 80 , com 500 famílias desabrigadas, e num cálculo aproximado sem os diques seriam 20.000 .

As escolas tiveram atividades suspensas.

https://gauchazh.clicrbs.com.br/geral/noticia/2013/08/enchente-em-sao-

leopoldo-e-a-maior-desde-1965-4249837.html. O risco do rompimento efetivo colocou em insegurança a população urbana.

7 Mapas referenciais podem ser consultados em

https://www.saoleopoldo.rs.gov.br/download anexo/PLANGEA\%20-\%20Volume\%202\%20-

\%20Final.pdf

Revbea, São Paulo, V. 16, № 4: 205-226, 2021. 
campo ficou patente a omissão reiterada de famílias que não atendiam ao apelo para a seleção dos resíduos sólidos. Por esta razão as (in)eficiências das práticas de pós-consumo, bem como a força do mercado imobiliário desencadeiam o enigma da decifração da percepção e das expectativas dos usuários de bens com valor de mercado.

A par da legitimação do saber científico e da colaboração de especialistas em orientar as escolhas técnicas da política ambiental, de acordo com Callon, Lascoumes e Barthe (2001) parece ecoar fortemente a possibilidade de legitimar a participação dos cidadãos residentes no local, funcionários públicos, atores sociais, entre outros. Este tipo de proposição reflete a perspectiva construtivista no campo sociológico e que não sucumbe às diferentes controvérsias sociotécnicas quando atores se mobilizam em meio às incertezas, porém dispostos a ouvir outros pontos de vista. Aos educadores ambientais, como segmento compromissado, vem a calhar a discussão das medidas a serem selecionadas pelos tomadores de decisão. Para que a resolução não seja confiscada por especialistas os educadores demandam a multiplicação de fóruns híbridos como "espaços abertos onde os grupos podem se mobilizar para discutir as escolhas técnicas que envolvem o coletivo" (CALLON; LASCOUMES; BARTHE, 2001, p 36).

Entre os vários conflitos manifestos no campo da pesquisa situa-se de pronto na concordância ou o endosso público dos resultados de estudos por especialistas: da pertinência de urbanização de áreas de banhados, da confiança e credibilidade de grupos do poder público dispostos a se apropriar e investir em práticas concernentes e incluir nas respectivas articulações representantes tanto científicos, quanto populares. Assim como os atores sociais, também o conhecimento científico nunca vem livre de interesses ou implicações éticas e sociais. A partir das entrevistas se pode mostrar que leigos são capazes de extensa reflexão sobre as relações sociais incidindo sobre o ambiente, bem como sobre as implicações da urbanização em áreas pertinentes ao rio em tempo de cheias. Destaca então, entre outros aspectos, as áreas sujeitas a inundação e em que a urbanização deveria ser impedida.

As obras de contenção de enchentes, com manutenção inadequada e danos significativos em sua estrutura, são, diante do sinistro, piores do que não ter obra alguma, pois, nesse caso, as inundações ocorrem gradativamente, ao contrário daquelas obras que possam romper provocando ondas de grandes dimensões (PENTEADO et alii, 2016, p. 165).

As periódicas inundações no Rio dos Sinos, associando aos cuidados com a água potável, geraram solidariedade, assistência social, cooperação, serviços públicos, financiamento de obras e o Comitêsinos (1989). De acordo com as experiências dos projetos desenvolvidos ficou evidenciada a diversificação de políticas em várias dimensões no gerenciamento de

revista brasileira educação ambiental 
desastres, demandando processos difusos de Educação Ambiental. Ao poder público cabe uma fiscalização regular quanto à manutenção do dique de contenção das águas e das bombas de transbordo, todavia em cujas atribuições conta com ações imprescindíveis por parte dos cidadãos. Ao mesmo tempo, também, a reformulação da legislação em face de desastres e das medidas mitigadoras, inclusive ampliando as parcerias público-privado. Neste movimento desabrocharam fóruns, com interfaces entre sociedade civil, Estado e mercado, com a pretensão de incidência em todos os aspectos do processo de preservação de bens ambientais. A elaboração de projetos de preservação navega na ambiguidade de defesa de direitos humanos ante o desastre e a construção de redes de proteção dos bens ambientais (áreas de banhado). Ou no dizer de Latour et al. (2018, p. 354) "sempre admirei os ambientalistas pela maneira como eles multiplicaram as questões a serem abordadas, mas também critiquei a representação geral que eles oferecem de suas muitas lutas úteis".

As iniciativas mencionadas são mais amplas do que uma gestão do desastre, uma vez que preveem ações de mitigação preventiva e um processo educativo ao longo de gerações. Este é o locus das experiências de justiça socioambiental. Atores com discursos considerados radicais, dentre os quais a retórica sobre os riscos e a Educação Ambiental, usualmente são considerados críticos, no sentido de encetar um debate consistente sob a rubrica das consequências da sociedade de risco, da modernização reflexiva e de outras teorias da política cultural na modernidade tardia (WYNNE, 2002). A resolução de dilemas ambientais com base em aplicações tecnológicas encontra algumas críticas efusivas e mais efetivas a partir da permanência ou surgimento de riscos ambientais e tecnológicos, como no caso de recentes desastres socioambientais na área do extrativismo e da mineração. Neste discurso de risco ambiental as incertezas são apreciadas pelas restrições quanto à avaliação e se a emergência de riscos possa ser eliminada pelo aprimoramento da ciência ou outras soluções tecnológicas.

\section{Da pesquisa à uma incursão analítica: resultados}

As condições de vulnerabilidades socioambientais resultam de processos sociais e mudanças ambientais. Assim, o contexto de risco favorece gerar afetados por desastres. As mudanças resultantes da degradação ambiental formam áreas vulneráveis (FREITAS et al., 2012), porém não se constitui aí a razão preponderante para a emergência de processos de Educação Ambiental. Se bem que depois do leite derramado se aprende a cuidar das relações implicadas entre recipientes, fogo e leite, porquanto algo parecido se sucede com as mudanças climáticas.

$\mathrm{Na}$ elaboração do texto o teor das entrevistas foi confrontado com a análise documental de origem e interpretações diversos forjadas pelos atores. Por meio dessa base empírica, abordamos o discurso e as práticas sociais, sempre considerando agentes em disputa. As recorrências discursivas 
possuem maior similaridade do que as práticas ambientais recorrentes. As duas dimensões foram abordadas levando em conta o espaço social em que emergiram. Confirma-se uma composição relacional dos cidadãos em face se seus espaços sociais, onde diferentes posições e capitais desiguais engendram disputas das mentes e corações.

A associação entre consumo e riscos se conflita no cuidado das águas, a parcimônia e a sobriedade quando se trata da formulação e efetivação de alternativas e empenho por resultados que impliquem em mudanças nas práticas culturais. Se as políticas que tomam o meio ambiente como objeto se revestem do ar da negociação, de outro parece que até o momento a diplomacia ratifica a forma impune ou o aviltamento dos bens naturais. Com isto se destaca uma ideia de Latour e outros (2018) de que estamos em uma situação em que a guerra não declarada à devastação torna impossível a articulação de conflitos reais.

O diagnóstico da pesquisa aponta para o paradoxo da insuficiência política e do protagonismo das referidas iniciativas para a recuperação e preservação da bacia hidrográfica, apesar de serem merecedoras de atenção de segmentos sociais e por investimentos públicos (RUSCHEINSKY, 2016). Urge, portanto, além de políticas ambientais específicas para o rio dos Sinos, iniciativas de projetos em educação para disseminar cuidados, buscando a mudança das práticas do pós-consumo e da percepção socioambiental.

Basicamente poderia o leitor requerer uma demonstração ou abordar de modo organizado os achados empíricos, as contribuições principais do estudo. Estas se revelam atreladas ao cominho das pedras, ou seja, as vias pelas quais os dados foram coletados. A princípio concebeu-se a existência de uma tipologia de conflitos ambientais, de ações de atores sociais, de ênfases das práticas educativas. Uma categorização dos achados decorre deste empreendimento. Por estes procedimentos foi possível identificar um leque de mecanismos de degradação ambiental, de iniciativas para o cuidado, de projetos de políticas públicas e a participação dos atores nos respectivos territórios da cidade. O impacto da organização social sobre o território e seus bens ambientais é objeto de reflexão no campo das ciências sociais, consolidando importante vertente temática teórica e metodológica. As conexões entre os âmbitos mencionados pode ser objeto de sistematização e categorização de acordo com o prisma adotado na abordagem:

1) os efeitos da ocupação intensiva de territórios, de modo que após o advento da preservação ambiental se constata um leque de problemas histórica e socialmente consolidados. Em suma, um processo irracional do desenvolvimento urbano e sem consideração adequada com a interdependência entre natureza e sociedade.

2) a compulsão pela ênfase econômica, que pode ser abordada como um potencial que possui incidência devastadora contra o patrimônio ambiental. Entre os exemplos, situa-se a água para consumo, entre 
outros prismas: após a poluição o coletivo paga caro para torná-la potável ou apta ao consumo humano.

3) a visão sistêmica da função primordial do consumo de objetos materiais e imateriais relaciona-se à dinâmica do lícito e ilícito, bem como à capacidade de persistência das relações sociais engendradas. Disto decorrem disputas territoriais e cultuais ou subjetivas de afirmação de códigos de condutas e de controle social.

4) os valores partilhados pelos agentes e a sua visão de mundo influenciam diretamente na triagem de temáticas e definição de critérios de elegibilidade para um problema vir a tornar-se objeto de política pública. Assim, os agentes públicos avalizam as situações críticas, identificadas e publicizadas por atores sociais, portanto decorrem de percepções sobre o mundo e as suas circunstâncias.

5) os educadores ambientais em certa medida possuem uma visão também decorrente de sua inserção na cultura do consumo, além do mais podem subsistir percepções em que, por vezes, prevalecem estereótipos e preconceitos. Como tal estes mobilizam concepções assimiladas nas suas experiências da vida social, ao mesmo tempo em que estas visões estão sujeitas a se transformarem.

6) a conformação da dimensão sistêmica na efetivação de projetos de Educação Ambiental por mais que evidências empíricas e contatos fortuitos estejam no cotidiano.

Os achados empíricos da presente pesquisa enunciam um questionamento quanto à variação do nível de satisfação individual dos cidadãos nos aspectos socioambientais. Entretanto, caberia um aprofundamento para incluir ou traduzir em variáveis e indicadores relacionadas ao campo ideológico: as contribuições da inserção na cultura de consumo e esmero nos cuidados com os bens ambientais.

O diagnóstico ante a multiplicidade de iniciativas, com uma diluição de ações e processos relativos à Educação Ambiental, especialmente quanto a alternativas ou propostas inovadoras destaca-se acima de tudo a insuficiência de sujeitos sociais ${ }^{8}$. $\mathrm{O}$ anseio de um protagonismo para engendrar mudanças socialmente significativas em face da ampliada degradação afeta de forma direta a urgência dos cuidados com a água potável. Ora, a constatação de atores sociais frágeis para consolidarem a mediação social do conhecimento (RUSCHEINSKY, 2014) mediado pelas inovações tecnológicas e outros saberes para os cuidados com o meio ambiente se deve em grande medida à vigência da obsessão em face da cultura de consumo. Esta última arrebata

8 A literatura aponta clivagens esta perspectiva. Pinto (1999) refere-se ao sujeito insuficiente em face de um duplo esgotamento do sujeito político, enquanto Carvalho (2004) hasteia o estandarte da formação do sujeito ecológico.

Revbea, São Paulo, V. 16, № 4: 205-226, 2021. 
corações e mentes, enfeitiça olhos, seduz os sentidos, sendo que educadores ambientais não estão imunizados diante deste deslumbramento, bem como impõe a predominância de argumentos provenientes do âmbito da mitigação.

As consequências históricas das inundações encontram-se atreladas à organização social e sua peculiar ocupação do território, onde o mercado imobiliário possui papel talvez preponderante, ao lado das ações naturais, como períodos, intensos ou prolongados, de precipitação pluviométrica. Em termos gerais, projetos de Educação Ambiental, por vezes territorializados, porém no mais das vezes desconsideram tal força política e cultural. Um debate alargado sobre os processos ou dinâmicas dos bens naturais leva em conta a existência de múltiplas linguagens: a natureza também fala, mas quais os mecanismos para escutá-la?

\section{Mudanças, práticas sociais e convivialidade}

Os instrumentos que permitam observar e apreender as relações e conexões entre os atores e seu entrelaçamento coletivo enseja uma perspectiva analítica que ajuda a decidir e responder às urgências requeridas pelas desafiadoras questões ambientais. Isto permite passar de uma perspectiva antropocêntrica para um ponto de vista descentralizado, que traduz para o plano principal os elementos fundantes para a satisfação humana como água, ar, espaço, solo e energia, que costumava permanecer numa dimensão ofuscada. Neste sentido, para a proposição de Educação Ambiental em situação de desastres ambientais mais do que a noção de rede (conexões fixas) acata e condiz com fluxos, entrelaçamentos, movimentos, conflitos, alianças (LATOUR et al., 2018). Estas circunstâncias dinâmicas se forjam na interlocução de ações propulsoras de atores humanos e nãohumanos em associação. Todavia, cabe compreender sob a ótica da Educação Ambiental que estas redes de entrelaçamento são contingentes e provisórias, bem como tal implicam dinâmicas históricas (PUHL, 2016).

A proposição de Educação Ambiental parece mais relevante quando se compreende que os hábitos da população contribuem para agravar a situação em períodos de alagamento, como um dos principais entraves. Ao mesmo tempo navega nas águas turvas do entroncamento de racionalidades. $O$ sentido da cidadania considera pertencimento e corresponsabilidade pelos bens naturais, porquanto a ação coletiva de Educação Ambiental auxilia na compreensão dos dilemas ambientais e alimenta a interpretação para reconhecer as causas dos fenômenos em destaque.

Pela circulação de informações é possível dar um significado ao papel da ciência quanto à explicação das interfaces socioambientais, de outro, os saberes outros, com suas ações podem gerar um efeito multiplicador. Isto constitui uma das descobertas para a efetividade das medidas de prevenção e de desvelamento próprio da Educação Ambiental. Parte dos impactos de desastre da inundação podem ser evitados com uma Educação Ambiental, voltadas para a situação de ocupação inadequada por pessoas do espaço dos 
banhados. As ações humanas e todo processo de urbanização, como o do consumo conspícuo, estão entre as causas da crise ambiental. Um conjunto variado de impactos socioambientais são tributados a este processo que se intensificou também no espaço social estudado, devido à demanda para aumentar o acesso ao consumo diversificado.

Sob a ótica da Educação Ambiental, a cidadania conecta-se à participação social $^{9}$, em que os indivíduos administram o seu direito na construção de sua visão de mundo, ou a construção do sujeito ambiental. Mesmo assim, há que reconhecer a vigência de uma lógica em que é atribuído ao Estado a responsabilidade do fornecimento de informações a propósito de ações e projetos voltados aos cidadãos. Neste sentido, "tanto o conhecimento dos fatores sociais, quanto os mecanismos disponibilizados podem estimular o engajamento político, com vistas à ampliação da democracia e do controle social, visando à qualidade das políticas de bem-estar social' (RUSCHEINSKY; TREIS, 2019, p. 608). Os autores enfocam que a participação se sucede desde a abertura de espaços para discussão em coletivos ou formatos organizativos, em particular para a deliberação sobre prioridades, a elaboração de estratégias de ação e o estabelecimento de canais de diálogo entre atores sociais e o poder público. Uma compreensão das ações individuais e coletivas sobre os efeitos dos diques alicerça a participação, bem como um senso crítico, no caso, envolve uma visão do processo histórico.

Os riscos e a vulnerabilidade são centrais para empreender esforços coletivos de redução dos efeitos de desastre. A deficiência de políticas públicas ambientais soa como uma questão transversal que alarga significativamente os riscos para indivíduos que já vivem na condição de múltiplas exclusões (IZUMI; SHAW, 2014). Embora muitas ações de Educação Ambiental afirmem uma perspectiva participativa em sua abordagem, há que reconhecer que permanecem paradoxais, assim como o envolvimento de atores sociais, porquanto existem obstáculos para reagregar o social como uma rede de interações.

Para um horizonte prospectivo à ética da alteridade na Educação Ambiental e do uso de bens naturais requer um processo ou uma visão política do diálogo de saberes. Ora neste domínio incide um conhecimento como resultado histórico em face da lógica da expansão do consumo entendido como qualidade de vida e da veleidade na apropriação capitalista do território. Ao pesquisador cabe estar atento à forma como se constituem as possíveis armadilhas da implementação da Educação Ambiental em circunstâncias de incerteza (NÉDÉLEC; SIMONNEAUX; MOLINATTI, 2017) e de quais alternantivas são mais convenientes e integradas às estratégias de questões emergentes. $\mathrm{Na}$ interdependência de fatores e indicadores, bem como um

9 Os fóruns participativos como espaços para prática da ecocidadania são destacados por Vicente e outros (2016), sob o prisma das percepções, bem como objetivamente por meio da análise de dados, com exame de indicadores.

Revbea, São Paulo, V. 16, № 4: 205-226, 2021. 
quadro de imprevisibilidade, Nédélec, Simonneaux e Molinatti (2017, p. 10) apontam para uma era das incertezas: "O desenvolvimento das tecnociências cria enormes interrogatórios para os quais as sociedades são incapazes de responder com certeza e universalidade". As decisões políticas no campo da Educação Ambiental adquirem maior eficiência se destacam a contribuição dos afetados; na prática propõem a inclusão da voz dos cidadãos nos desdobramentos de projetos ambientalmente responsáveis e socialmente participativos. Isto requer capacidades de multiplicar informações que possam gerar ações de cuidados consigo e com o ambiente; ou em outros temos uma brigada ecológica em defesa, monitoramento e protagonismo.

Com isto se advoga a implementação da reflexividade como capacitação ao reconhecimento do papel de cidadãos na sociedade do conhecimento, de cuidados múltiplos no território urbano (RUSCHEINSKY, 2016). Os atingidos do campo deste estudo relatam que da parte do poder público a ação efêmera ou a superficialidade ou senão que prevalece a dimensão emergencial. $\mathrm{Na}$ pesquisa de campo se constataram problemas quanto ao retorno da burocracia do Estado, bem como sobre a ação de atores sociais, para o auxílio de objetos, alimentos e apoio psicológico. Diversos atores sociais, como associações de moradores e alguns docentes de escolas buscaram alertar à população para a preservação ambiental, práticas após desastres e projetos sociais.

Em diversos anos ocorrem inundações e que mostra que o ser humano pode intensificar ou mitigar os desastres, pois junto aos mecanismos para 0 transbordo das águas ameaçadoras foram encontradas toneladas de resíduos. Ora, neste sentido a crise ambiental é também uma crise epistemológica, para não dizer um certo fracasso das inovações científicas.

Dentro da área geográfica do Rio dos Sinos diversos projetos de preservação são desenvolvidos em entorno do rio, como, da potabilidade de suas águas. Alguns dos projetos foram forjados e são realizados pelo Comitesinos ${ }^{10}$, na sua preocupação com práticas e mudanças nas questões ambientais, com limites perceptíveis pelas lentes das ciências sociais tendo em vista que esbarram em mecanismos políticos, jurídicos, culturais devido a origem social de seus membros, as alianças de forças políticas e um sistema de práticas e epistemologias plurais (FLORIANI, 2019).

A partir das articulações deste órgão evitou-se o colapso do abastecimento devido à escassez de água no leito do rio, mostrando a versatilidade de um colegiado regional que estabelece negociações entre usos conflitivos, cuja perspectiva pressupõe um processo de Educação Ambiental ou de consideração da alteridade. Se há indicadores em construção, existem questões que demonstram o grau de percepção da magnitude da Educação Ambiental (ABREU, 2016) como forjar o empenho para a ligação do esgoto

10 Entre eles denominamos: Peixe Dourado, Monalisa, Verdesinos, Recomposição da mata ciliar, Programa Permanente de Educação Ambiental da Bacia do Rio dos Sinos (PPEA), Celebração das águas, formação de docentes multiplicadores, etc

revista brasileira educação ambiental 
sanitário de suas residências à rede coletora pública. Neste sentido, há informações transitando de forma lenta e parcela da população, tentando qualificar o seu senso crítico da relevância de cada qual fazer a sua parte, conjuntamente com a ação de políticas públicas ambientais.

A Educação Ambiental é citada no cotidiano de diversos segmentos ou percepções individuais e contemplada por projetos realizados fora do contexto do Comitesinos e do SEMAE, como escolas, ONGs e associações. Assim, há uma multiplicação de saberes com ênfase à inquietação com saúde pública, com a sobriedade de consumo, com a escassez e os alagamentos. Estas expectativas decorrem como reflexos das ações e práticas sociais e desafiam as capacidades do poder público e as iniciativas de Educação Ambiental. Estas realmente estão desafiadas a atestar resultados socialmente percebidos no cotidiano, na ambição da reconfiguração do território urbano. De fato, significa mobilização de saberes e um olhar investigativo, mesmo que difuso.

Os moradores de locais de risco de inundações comentam a respeito do poder público incentivar um programa de benefícios para trabalhadores que recolhem resíduos sólidos deixados por outros moradores em locais indevidos. Também coletamos alguns testemunhos intrigantes quanto às funções da brigada ecológica com a atribuição da vigilância e distribuição de recomendações concernentes às práticas sobre as condições socioambientais dentro dos bairros afetados, além de alertar sobre a previsão de enchentes, o descarte adequado de determinados materiais, a cooperação, entre outras ações.

\section{As barreiras artificiais: a luta política contra novos diques}

A bacia hidrográfica em questão apresenta uma extensa área úmida (usualmente tidas como banhados), expressões da biodiversidade e reservatórios temporários em decurso de chuvas intensas. Segundo Silva e Kuhn (2017) existe uma intensa simbiose denominada de "os banhados em nós e nós nos banhados". Os autores ainda conjeturam que nestas circunstâncias se conforma um patrimônio cultural, material e natural da biodiversidade. A educação para a preservação desta água potável pode demonstrar o quanto a população preza e considera os seus patrimônios. Por meio de registros históricos da região em destaque e de aspectos simbólicos faz todo sentido o imaginário e o paradoxo de que os banhados estão em nós, assim, como nós nos banhados.

A legislação protege as espécies, mas não as defende pela sua dimensão cultural. Aliando-se os aspectos simbólicos com as questões ambientais considera-se relevantes os ecossistemas, pois que fundamentais para qualidade e quantidade das águas e para a manutenção da biodiversidade. $O$ tombamento das planícies de inundações como produto de processos difusos de Educação Ambiental parece se tornar viável com o apoio 
comunitário na medida do reconhecimento do outro (RUSCHEINSKY, 2016), devido ao volume de cidadãos prejudicados pelas inundações.

Entre os achados se reconhece que existem explicações para os efeitos tão díspares da legislação e das políticas na vida cotidiana: como no caso, entre adesão entusiasmada à diminuição do consumo e à coleta seletiva e, de outro, a rejeição ou menosprezo. Em grande medida as adesões a agenda ambiental repousam na existência de políticas ligadas ao setor e suas respectivas conexões com políticas em face das questões sociais.

Para apontar outras dimensões, de alguma forma tensionadas na exposição acima, nos reportamos à recente luta política visando evitar a construção de novos diques. Se a questão social também incluísse os nãohumanos outras contradições se explicitariam. Neste caso em particular poderíamos concluir que se trata de cidadãos em uma compostura em que se põem a lutar contra a sua própria condição de consumidores.

Os achados empíricos dizem respeito às peripécias em isolar a questão ambiental das demais questões sociais e assim ser capaz formalmente de identificar preferências em face das políticas ambientais. Tanto na gestão das políticas, quanto no âmbito escolar a temática ambiental está submetida a questões concorrentes, ao passo que poderiam ser convergentes. Em última instância estas também resultam de escolhas políticas de indivíduos e atores sociais. Além da falta de disponibilidade de dados para elaborar estudos comparados robustos. Ainda resulta dos estudos realizados a fragilidade de uma performance das convicções ante o apelo para expandir os cuidados ambientais.

$\mathrm{Na}$ realidade a pesquisa de campo atesta que são temáticas ambientais de tênue adesão, e como tal cabe a interrogação porque a defesa da própria vida ou bens não se reverte em convencimento ou para além da discussão de somar forças para a realização. O modelo de organização da sociedade que se alicerça no uso intensivo do solo, da água, dos minerais, da biodiversidade e outros recursos naturais se direciona para a utilização predatória. Ora, a concepção de Educação Ambiental questiona a visão onde o progresso em ritmo contínuo se justificaria para alcançar um suposto bem-estar social para os cidadãos de um território, ao mesmo tempo incorpora o questionamento de injustiças social e ambiental. Mais do que isto, a situação em destaque permite endossar que o desencadeamento de políticas sociais em grande medida justamente é impelido pelas injunções a ignorar os fluxos da natureza externa e conhecida objetivamente pela ciência.

Do ponto de vista prático, o sistema de proteção de inundações requer a devida manutenção, pois a cada intensa chuva ou prolongada faz-se presente a aflição em saber se a capacidade do sistema dos diques realmente conseguirá efetuar o seu primordial objetivo: proteger a área urbanizada em face de inundações. De acordo com informações do ambientalista de longa trajetória, Arno Kayser, existem crescentes questões apontadas acerca do longevo funcionamento do sistema de diques no Rio dos Sinos. A apreensão é

revista brasileira educação ambiental 
de que esteja chegando o ponto crucial em que, se não houver um processo mais efetivo de Educação Ambiental, bem como um processo recorrente de manutenção, as suas funções originais podem entrar em colapso ${ }^{11}$. Segundo Adolf Klein (na ocasião presidente do Comitêsinos) a temática das inundações e a sua conexão com processos de Educação Ambiental foi recorrente nos eventos públicos realizados pelo Comitê em face do processo de elaboração do Plano de Bacia Hidrográfica.

Estão submetidos a polêmicas as ocupações das planícies sujeitas a inundações e em que medida atestam efeitos adversos ao meio ambiente por causa dos impactos adversos. Diante das circunstâncias em curso percebe-se que a remoção das populações em áreas de risco significa um alto custo político e econômico, mas o impedimento da instalação de novas moradias intensificando e alargando o espaço urbanizado é uma questão de segurança cidadã. A razão para a luta contra novos diques e em favor da população residente próxima aos existentes contém a perspectiva da Educação Ambiental como um dos alicerces.

Ao ser perguntado sobre o nexo entre a construção (in)apropriada da Rodovia 448 (rodovia que liga a capital Porto Alegre à região do vale do Rio dos Sinos, inaugurada em 2013) e as inundações urbanas, Jackson Müller respondeu que existe um acompanhamento quanto às demandas postas em questão pelos gestores dos municípios da região: "Verificou-se que a Rodovia foi construída no traçado previsto do dique projetado na década de 1970, podendo servir como contenção de inundações provocadas pela elevação do rio dos Sinos. A conurbação pode estar cobrando esse preço na região metropolitana, uma vez que temos moradias construídas em áreas de risco". A situação do pleito de uma extensão de diques associados a uma Rodovia pode decorrer de um largo conjunto de fatores que perpassam outras questões estruturais de falta de planejamento nas cidades. Todavia, já existe disponível um mapa interativo da planície de inundação ${ }^{12}$ que serve como uma ferramenta, permitindo consultar os pontos que estão dentro ou localizam-se fora de área usual de inundação.

Qual seria a solução alternativa ante as inundações? Seriam realmente os diques, ou poderia haver alternativas? Assim se realizam estudos a respeito deste empreendimento e de outras opções, com um possível resultado para sustentar políticas públicas. Ora, na realidade, se realizam muitos diagnósticos ${ }^{13}$, porém verifica-se um descompasso entre estes e as ações

11 Algo similar aconteceu no ano de 2017 em Porto Alegre, quando o sistema de bombas falhou em alguns pontos da cidade que estariam protegidos, mas que ficaram inundados, não pela água vinda da enchente, mas pela água da cidade que não foi removida para o lado de dentro dos diques.

12 Disponível em http://www.comitesinos.com.br/au/

13 Em 2017 foi levado a efeito "Estudos de Alternativas e Projetos para Minimização do efeito de Cheias na Bacia do Rio dos Sinos" com Valor do Contrato de 10 milhões de reais. 
políticas que engendrem as alternativas sugeridas. Sendo assim, existem efetivamente objeções a novas formas de contenção das águas para debelar inundações: a preservação das funções dos banhados, os custos de manutenção e os planos governamentais asseverando ganhos do mercado imobiliário.

A questão tecnológica e a educacional que confirmam os aspectos que envolvem a funcionalidade dos diques, de um lado é imprescindível para as soluções consolidadas por meio de políticas públicas e, de outro, parece que ainda restam insuficiências em si mesmo na medida em que se requer mais intensa participação social. Diante deste fato Ruscheinsky e Treis (2019, p. 607) mencionam o fenômeno da fragilidade de mecanismos que "consolidassem a representatividade dos atingidos em sua heterogeneidade; a realização de audiências públicas como mecanismo de debate e de auscultar as demandas dos atores sociais ou fóruns de mobilização social".

Enfim, a luta contra novos empreendimentos de delimitação do fluxo das águas como políticas públicas de Educação Ambiental e de contenção de inundações obtém um dividendo na medida em que a plenária do Comitêsinos emitiu parecer contrário a qualquer iniciativa para formatar novas barreiras artificiais que obstruam o espaço ocupado periodicamente pelas águas do rio dos Sinos.

\section{Conclusões}

Particular importância para a projeção de iniciativas de Educação Ambiental pode ser atribuída aos efeitos de cenários territoriais e as peculiares questões sociais e políticas. A princípio qualquer espaço social pode suscitar aprendizados inerentes à Educação Ambiental, bem como fundamentar e influenciar políticas públicas específicas para o espaço urbano.

Os movimentos, o associativismo e os atores em ação dentro de determinado espaço territorial enfrentam conflitos e desafios associados para lidar com políticas públicas ambientais tendo em vista as divergências e visões do nexo entre sociedade/natureza, entre reduzir consumo e descartar resíduos. Observamos esforços politicamente motivados para forjar, ampliar e institucionalizar a Educação Ambiental visando qualificar o espaço urbano sob a dimensão dos direitos humanos. Uma observação atenciosa na pesquisa de campo lança luz sobre disputas ideológicas que permeiam o campo de efetivação de políticas públicas e, em particular, os conteúdos inerentes aos processos de Educação Ambiental. A diversidade de perspectivas envolvidas na ótica da mitigação dos efeitos dos desastres ambientais exige por parte de pesquisadores um zelo para distinguir acomodação ou resiliência de uma visão crítica da Educação Ambiental.

Não por último, compreende-se que há suscetibilidades na abordagem da Educação Ambiental. De um lado, o esforço de cientista social para a busca da objetividade possível e alicerçar a narrativa em dados factuais no conflito

revista brasileira educação ambiental 
das interpretações. De outro, verifica-se a mescla entre o que é na realidade a Educação Ambiental como processo social e o que se almeja que ela efetivamente poderia vir a ser como projeto ou aspiração.

Entre as descobertas nesta pesquisa situa-se o fato de que os fenômenos estudados podem ser enfocados como práticas que visam a construção de comunidades de aprendizagem em face dos desafios ambientais. Isto ocorre pelo modo de problematizar a própria práxis dos integrantes de um mesmo espaço, ao remeter a processos de observação da biodiversidade, dos grupos sociais diferentes que interagem e que conflitam sobre as óticas da proteção ambiental e do desenvolvimento social.

Nesta perspectiva, o esgoto doméstico e resíduos sólidos são um dentre os desafios imediatos de uma gestão pública sustentável. Em termos difusos existe um passivo ambiental a ser incorporado nas discussões, por mais que o território em destaque não se compare a um lixão ou aterro controlado, todavia o processo de fiscalização e monitorando do esgoto e dos resíduos se assemelha a um processo de mitigação (redução de danos). De certo modo, o monitoramento das políticas públicas de contenção das inundações e o destino dos resíduos se converteram em focos das mobilizações no âmbito da Educação Ambiental. Ao mesmo tempo as cidades do entorno estão sob a esfera da "exportação de lixo" de um lugar de origem a sua destinação há um percurso considerável (outros municípios), acarretando emissão de gases, entre outros passivos.

Os impactos dos desastres ambientais sobre as condições de vida estão diretamente vinculados a um processo contínuo de degradação das bases materiais da vida ou de bens naturais da região do vale do Rio dos Sinos. E bem mais do que isto ou mais do que reinventar questões para movimentos ambientalistas, trata-se de reconhecer pelas lentes da Educação Ambiental o difícil encontro entre indivíduos devastados e dilacerados, cada qual tentando conectar-se civil ou violentamente com outro como numa "jaula de ferro" devido à armadilha do consumo e outros mecanismos. Esta complexidade requer o refinamento de argumentamos também de educadores e pesquisadores ambientais, com aprimoramento de arcabouços teóricos e metodológicos para configurar as contradições engendradas em face da sustentabilidade.

A partir de todos os dados abordados anteriormente, justifica-se a motivação para outros estudos sobre as práticas de Educação Ambiental, ainda há possibilidades de investigação diante do ciclo de políticas ambientais e seus desdobramentos voltadas aos desastres socioambientais, que ainda afetam diversas regiões do Brasil, assim como outras dimensões envolvendo a questão das inundações junto ao Rio dos Sinos. 


\section{Referências}

ABREU, N. J. et al. O papel da Educação Ambiental no desenvolvimento da percepção dos riscos de inundações e prevenção de acidentes e desastres naturais. Revista Brasileira de Educação Ambiental, v. 11, n. 1, p. 97-107, 2016.

CALLON, M.; LASCOUMES, P.; BARTHE, Y. Agir dans un monde incertain. Essai sur la democratie technique. Paris: Seuil, 2001.

CAMPOS, I. M.; ALVES, J. B. Participação social na gestão de resíduos sólidos na cidade de Teixeira (PB). Revista Brasileira de Educação Ambiental, v. 14, n. 4, p. 323-339, 2019.

CARVALHO, I. C. M. Educação Ambiental: a formação do sujeito ecológico. São Paulo: Cortez, 2004

FLORIANI, D. Ciência, etnociências e saberes locais: apontamentos para refletir sobre o debate teórico e as práticas do socioambientalismo, in SHIRAISHI N., J. et. al (orgs.). Problema ambiental: naturezas e sujeitos em conflitos. São Luís: Edufma, 2019, p. 25-47

FREITAS, C.M. et al. Vulnerabilidade socioambiental, redução de riscos de desastres e construção da resiliência: lições do terremoto no Haiti e das chuvas fortes na Região Serrana. Ciências Saúde coletiva, v. 17, n. 6, p. 15771586, 2012.

HARREMOËS, P. et al. The precautionary principle in the 20th century. Late lessons from early warnings. London: Earthscan Publications, 2002.

ISSBERNER, LR; LÉNA, P. (ed.). Brazil in the anthropocene: conflicts between predatory development and environmental policies. Londres, NYC, Routledge Environmental Humanities, 2017.

IZUMI, T.; SHAW, R. Role of civil society organizations in policy and advocacy in risk reduction. In: SHAW, R.; IZUMI, T. (eds). Civil Society Organization and Disaster Risk Reduction. Springer, Tokyo, 2014. p. 15-27.

JACOBI, P. Educação Ambiental: o desafio da construção de um pensamento crítico, complexo e reflexivo. Educação e Pesquisa, v.31, n.2, p.233-250, 2005

KUHLICKE, C. et al. Contextualizing social vulnerability: findings from case studies across Europe. Natural Hazards, v. 58 (2), p. 789-810, 2011.

LATOUR, B. Para distinguir amigos e inimigos no tempo do Antropoceno. Revista de Antropologia, v. 57, n.1, p.11-31, 2014.

LATOUR, B. et al. Down to earth social movements: an interview with Bruno Latour. Social Movement Studies, v. 17, n. 3, p. 353-361, 2018.

NÉDÉLEC, L.; SIMONNEAUX, L.; MOLINATTI, G. Éduquer dans un monde incertain: quel cadre pour comprendre comment les enseignants appréhendent les incertitudes des questions socialement vives? Journal of education, v. 5, n. 02, p. 10-24, 2017. 
PENTEADO, A.F et al. Riscos Associados ao Sistema de Controle de Enchentes no Vale do Rio dos Sinos. Territorium, n. 19, p. 161-168, 2016.

PINTO, C. R.J. O sujeito insuficiente: a dupla face do esgotamento do sujeito político no fim do século XX. In: SANTOS, J.V.T. (Org). Violência em tempos de globalização. São Paulo: Hucitec, 1999, p. 101-117.

PUHL, M. J. Educação Ambiental: compreender o contexto socioambiental. Revista Brasileira de Educação Ambiental, v. 11, n. 4, p. 184-196, 2016.

ROSA, C. D.; PROFICE, C. C. Que tipo de Educação Ambiental e para quem? Fatores associados a atitudes e comportamentos ambientais. Revista Brasileira de Educação Ambiental, v. 13, n. 1, p. 111-125, 2018.

RUSCHEINSKY, A. Políticas públicas ambientais, mediação da educação e o bem natural da água, In NEUMANN, L. (Org). Desafios da educação para os novos tempos. Porto Alegre: Evangraf, 2014, p. 229-247.

RUSCHEINSKY, ALOISIO. Protagonismo de atores coletivos e políticas ambientais com a inclusão do outro. In: LOPES, J. R.; STEIL, C. A.; LEISTNER, R. M. (Org.). Políticas culturais e ambientais no brasil: da normatividade às agências coletivas. Porto Alegre: Cirkula Ed., 2016, v. 2, p. 83-106.

RUSCHEINSKY, A.; TREIS, M. Desastre ambiental, atores sociais, políticas públicas e espaços passíveis de participação. Revista de Psicologia Política, v. 19, p. 602-614, 2019.

SECCHI, L. Análise de Políticas Públicas: diagnóstico de problemas, recomendação de soluções. São Paulo: Cengage Learning, 2016, 238p.

SILVA, D. C.; KUHN J., N. Projeto banhados em nós-patrimônio cultural, material e natural da Bacia Hidrográfica do Rio dos Sinos. Revista Eletrônica Científica da UERGS, v. 3, n. 4, p. 711-722, 2017.

VICENTE, A. C. V. et al. Os fóruns participativos como espaços para prática da ecocidadania. Revista Brasileira de Educação Ambiental, v. 11, n. 2, p. 4353, 2016.

WITTLER. Projeto Contra Cheias no Vale do Rio dos Sinos, em São Leopoldo, Novo Hamburgo. Disponível em: <http://www.wittler.com.br/>. Acesso em ago. de 2020.

WYNNE, B. Risk and environment as legitimatory discourses of technology: reflexivity inside out?. Current sociology, v. 50, n. 3, p. 459-477, 2002. 